\title{
DISCIPLINA, CORPO E CIVILIZAÇÃO ${ }^{1}$
}

\author{
José Gonçalves Gondra*
}

\begin{abstract}
RESUMO
Este artigo se encontra organizado em torno de dois núcleos. No primeiro, exploro uma possibilidade de se pensar o exercício do poder na modernidade e, no segundo, procuro demonstrar como o poder incide sobre a vida e sobre os corpos, analisando casos específicos, de modo a demonstrar a extensão da vontade de disciplinar a vida e os corpos. Para tanto, examino os dispositivos voltados para a normalização dos corpos em manuais de higiene, na literatura de caráter autobiográfico e nos regulamentos de instituições voltadas para o atendimento de cegos e surdos-mudos. No exame deste material, que remete à experiências francesas, inglesas e brasileiras, o que se pode observar é a expansão da razão e a submissão dos corpos como técnica que objetiva dobrar as vontades.
\end{abstract}

PALAVRAS-CHAVE: História da educação. Educação física. Poder.

\section{RESUMÉ}

Cet article se trouve organisé autour de deux noyaux. Dans premier, j'explore une possibilité de penser l'exercice du pouvoir dans la modernité et, au deuxième, je cherche à démontrer comme le pouvoir arrive sur la vie et sur les corps, en analysant des cas spécifiques, afin de démontrer l'extension de la volonté de disciplinaire la vie

* Professor adjunto da UERJ. Procientista UERJ/FAPERJ e Pesquisador do CNPq. ' Uma versão deste texto foi apresentada no XV Congresso Brasileiro de Ciências do Esporte, no GT "Memórias da Educação e Física e do Esporte”. O evento ocorreu em Recife, entre 16 e 21 de setembro de 2007. 
et les corps. Pour de telle façon, j'examine les dispositifs tournés pour la normalisation des corps dans des manuels de l'hygiène, dans la littérature de caractère autobiografique et aux règlements d'institutions tournées pour la participation d'aveugles et surdsmuets. Dans l'examen de ce matériel, lequel il envoie aux expériences françaises, anglaises et brésiliennes, ce qui se peuvent observer est l'expansion de la raison et la soumission de corps comme technique qu'objective plier les volontés.

MOTS-CLES: Histoire de l'éducation. Education physique. Pouvoir.

Este texto encontra-se organizado em torno de dois núcleos. No primeiro, exploro uma possibilidade de se pensar o exercício do poder na modernidade e, no segundo, procuro demonstrar como o poder incide sobre a vida e sobre os corpos, analisando casos específicos, de modo a demonstrar a extensão da vontade de disciplinar a vida e os corpos.

Na partida, um primeiro corte que me pareceu razoável seria pensar algo como o "corpo na escola". Cortado nestes termos, julguei que haveria necessidade de chamar atenção para o fato de que as preocupações com a física dos corpos, sua forma, rentabilidade e robustez comparece na disciplinarização dos saberes específicos, como a Ginástica e Educação Física, mas também nas preocupações com os edifícios, sua arquitetura e usos, quantidade de alunos, sexo, alimentação, tempo escolar, demografia e desenvolvimento de outros saberes, por exemplo. De modo geral, estes aspectos a respeito da vida e dos corpos podem ser enfeixados no campo das preocupações médico-higiênicas e religiosas, o que já vem sendo explorado em estudos desenvolvidos por Tarcísio Vago (2002), Marcus Taborda (2003) e Fernanda Paiva (2003), para me referir aos que conheço um pouco mais. Sendo assim, ao seguir esta trilha correria o risco de "bater em solo já batido" ou de "arar terreno já arado". Deste modo, para tentar evitar o efeito de saturação, esta espécie de repetição, optei 
por correr outro risco, tentando tatear outros pontos para o debate.

Como pensar o corpo como problema em uma reunião da qual participam os principais pesquisadores e professores que dedicaram longos anos de estudo a este domínio/objeto? Procurei enfrentar o desafio a partir de um programa de trabalho em que procurei combinar reflexões relativas a uma forma de funcionamento do poder (o disciplinar) e seus efeitos sobre os corpos. É, pois, com este tipo de ferramenta que pensei em participar do debate acerca dos corpos a serem disciplinados nas casas, escolas, fábricas, prisões, oficinas, igrejas, recolhimentos, hospícios, quartéis, hospitais e nas ruas. Trata-se, portanto, de fazer aparecer um bloco de instituições nas quais conjuntos mais ou menos móveis de procedimentos são ativados, legitimando ações voltadas para a formação dos sujeitos e de seus corpos. É, portanto, por meio desta ótica que pretendo pensar o corpo como um problema, como uma espécie de suporte, de matéria na qual se inscrevem as marcas da disciplina que caracterizam o mundo moderno.

\section{Uma disciplina para os corpos}

Podemos afirmar que o corpo é submetido desde a concepção até a morte. No intervalo da vida, há um tempo em que as experiências corporais se encontram mais reguladas pelo espaço da casa e, outro tempo, em que tal regulagem se processa de modo articulado com outras instituições sociais específicas, como hospitais, escolas, igrejas e prisões, por exemplo.

Para pensar este esquema regulatório ramificado, sob o qual é possível inscrever os corpos, gostaria de explorar, ainda que sumariamente, aspectos da teoria do poder, apoiado, sobretudo em algumas reflexões foucaultianas. Aqui, no entanto, uma pequena, mas necessária digressão.

Ao fazer um inventário da circulação da produção intelectual do Michel Foucault no Brasil, tenho observado que o Foucault

Educ. e Filos. Uberlândia, v. 23, n 45, p. 65-100, jan./jun. 2009. 
consumido no meio acadêmico, especialmente no campo da educação e da história da educação, é o da teoria do poder, o que tem sido feito com base nos livros "Vigiar e Punir" e pela coletânea "Microfísica do Poder". O emprego de termos como "microfísica, arqueologia, capilaridade, genealogia, biopolítica, biopoder e panoptismo" foram vulgarizados e, por vezes, em alguns casos, aparecem despregados da teoria. Cabe sublinhar que a evidência de um emprego instrumental de termos ou categorias associados à produção intelectual foucaultiana precisa ser mais testada, inclusive em outros domínios ${ }^{2}$.

Para se ter uma idéia da força da presença de Foucault no território da História da Educação, em uma tentativa de síntese, as referências mais recorrentes são aos livros "Vigiar e punir" e "Microfísica do poder", o que pode ser explicável em dois níveis. Um, a facilidade de acesso e de leitura, tendo em vista o fato de tais livros encontrarem-se traduzidos em inglês, espanhol e português. Cabe sublinhar que as referências aos textos em francês ou em outras línguas estrangeiras comparecem com mais freqüência nos artigos de autores estrangeiros, que tendem a citar o livro traduzido em sua língua materna. Portanto, como era de se esperar, a língua se constitui em um aspecto decisivo para se pensar o regime de circulação dos livros. Elemento que, por exemplo, ajuda compreender a rarefação dos "Ditos \& escritos" nos artigos dos autores brasileiros, pois só recentemente foram organizados na França e, mais recentemente, traduzidos e publicados no Brasil, em 5 volumes, sendo o último de 2004. A tradução também torna compreensível a ausência de remissão aos cursos do Collège de France, cuja publicação em língua portuguesa ainda vem se fazendo e, o último deles, "O poder psiquiátrico" só foi publicado em 2006.

Considero, portanto, que a presença do livro "Vigiar e punir" nos estudos de História da Educação não pode desconsiderar a chave

${ }^{2}$ Reflexões a respeito das apropriações de Foucault no campo da história da educação podem ser conferidas em Gondra, 2005.

Educ. e Filos. Uberlândia, v. 23, n 45, p. 65-100, jan./jun. 2009. 
da tradução. No caso do Brasil, segundo levantamento recente ${ }^{3}$, este livro já vendeu 122.229 exemplares; um verdadeiro fenômeno editorial, se considerarmos as tiragens dos livros acadêmicos que raramente ultrapassam dois mil exemplares ${ }^{4}$. Em média, este livro, desde sua tradução no Brasil, em 1977, teve uma nova edição a cada ano, com uma única modificação da capa nestes 30 anos. O que pode explicar este fenômeno? O objeto em exame, a qualidade da pesquisa desenvolvida, uma redação acessível e, sobretudo, uma destinação ampla, visto que se presta para pensar as diversas instituições disciplinares instauradas na modernidade, como o quartel, o asilo, o hospital e a escola. Movimento de institucionalização geral, cuja finalidade, segundo Foucault (1991), foi o de suavizar as penalidades. Trata-se, portanto, de uma reflexão que procede a uma espécie de diagnóstico de nossa sociedade, oferecendo uma chave para compreender seu funcionamento, por meio do exame das instituições criadas e pelo modo como o poder nelas é exercido.

A difusão, como é sabido, se encontra inevitavelmente associada ao debate editorial, mas no caso do Foucault, este não é o único fator que contribui para a compreensão deste fenômeno. Um segundo elemento deve ser considerado, na medida em que a popularização de Foucault entre nós também se encontra articulada às suas viagens ao Brasil, à elaboração e publicação de trabalhos de brasileiros de inspiração foucaultiana no final dos anos 70 do século passado e também a rede de sociabilidade tecida com professores no Rio de Janeiro, São Paulo, Minas Gerais, Bahia e Pernambuco, por exemplo 5 .

Um terceiro plano que ajuda a pensar as apropriações foucaultianas pode ser associado à renovação no campo das Ciências

${ }^{3}$ Cf. MENDONÇA, 2007.

${ }^{4}$ O livro foi contratado pela Editora Vozes em 19 de fevereiro de 1975 e sua primeira edição saiu dois anos depois, em setembro de 1977. A editora já chegou a fazer duas tiragens deste livro em um único ano.

${ }^{5}$ Para saber mais a este respeito, cf. GONDRA \& KOHAN, 2006.

Educ. e Filos. Uberlândia, v. 23, n 45, p. 65-100, jan./jun. 2009. 
Sociais no Brasil, a partir dos anos 80 . Este pode ser considerado um fator adicional que animou a busca de novas referências e o conseqüente "arejamento" verificado em diferentes campos, o que terminou por criar condições para se problematizar os fundamentos teóricos que, de modo dominante, sustentavam as reflexões até então desenvolvidas.

Com esta digressão acerca da difusão da produção foucaultiana, gostaria de assinalar que se ela fornece pistas, estas ainda são insuficientes para examinarmos o impacto de sua teoria do poder na compreensão da chamada sociedade disciplinar. Caberia ainda indagar, acerca dos objetos interrogados a partir da "caixa de ferramentas" foucaultiana e como ela tem sido manejada nestes estudos.

Diante deste reconhecimento da produção e circulação foucaultiana, desta espécie de diagnóstico é que pretendo trazer aspectos do debate acerca da teoria do poder, trilhando caminho semelhante ao de Judith Revel (2006), no sentido de reler o "Vigiar e punir". No entanto, desenvolvi uma estratégia distinta. Enquanto ela procura rebater as críticas à teoria do poder, apanhando elementos no interior do próprio livro que ajudam a responder à crítica do "desaparecimento do sujeito", presente em usos bem determinados a que este texto vem sendo submetido. De minha parte, procurei ler a teoria do poder desenvolvida e abraçada por Foucault, tomando por base seu curso de 12 aulas ( 7 de novembro de 1973 a 6 de fevereiro de 1974), no Collège de France, publicadas na França em 2003 e traduzidas no Brasil em 2006 sob o título "O poder psiquiátrico". $\mathrm{O}$ que justifica esta estratégia? Inicialmente porque, neste curso, Foucault explora um campo de problematização que dialoga com o que já estudara, no caso a loucura, e com algo que ainda estava por vir, no caso, o livro "Vigiar e punir", de $1975^{6}$. É esta espécie de recuo, de antecipação, da elaboração de um pensamento acerca

${ }^{6}$ Para uma compreensão do curso de 1973/1974 no âmbito da produção de Michel Foucault, cf. o posfácio de Jacques Lagrange. 
do funcionamento do poder na modernidade que, neste momento, interessa mais de perto.

No final da primeira aula, focado no exame do asilo psiquiátrico e no seu funcionamento, ele utiliza pela primeira vez o termo "microfísica do poder", deixando um espaço aberto para a continuidade da reflexão na aula seguinte. Nesta, descreve a macrofísica do poder, associado ao poder soberano, que se manifesta essencialmente pelos símbolos de força fulgurante do indivíduo que o detém. Aquele seria distinto do poder disciplinar, discreto, repartido, que funciona em rede e cuja visibilidade encontra-se tão somente na docilidade e na submissão daqueles sobre quem, em silêncio, ele se exerce. (2006, p. 28)

$\mathrm{Na}$ terceira aula, ao precisar um pouco mais sua compreensão do poder disciplinar, Foucault se aproxima do problema que mais nos interessa, isto é, das articulações entre corpo-poder. Para ele, o poder disciplinar nada mais é que uma forma de certo modo terminal e capilar. Trata-se de uma última intermediação, certa modalidade pela qual o poder político, os poderes em geral vêm, no último nível, tocar os corpos, agir sobre eles, levar em conta os gestos, os comportamentos, os hábitos, as palavras, a maneira como todos esses poderes, concentrando-se para baixo até tocar os próprios corpos individuais, trabalham, modificam, dirigem "as fibras moles do cérebro". Neste sentido, o poder disciplinar seria certa modalidade, bem específica de nossa sociedade, do que se poderia chamar de contato sináptico corpo-poder (idem, p. 50-51). Considerando estas coordenadas gerais, o poder disciplinar é descrito com base em três características:

1 - O poder disciplinar implica em uma apropriação total ou tende a ser uma apropriação exaustiva do corpo, dos gestos, do tempo, do comportamento do indivíduo. O exemplo oferecido para demonstrar este traço é o aparecimento do sistema disciplinar no exército a partir de meados do século XVII, com o instituto do aquartelamento. A disciplina começa a ser o confisco geral do corpo, do tempo, da vida.

Educ. e Filos. Uberlândia, v. 23, n 45, p. 65-100, jan./jun. 2009 
2 - O poder disciplinar é contínuo, estando perpetuamente sobre o olhar de alguém ou na situação de ser olhado. Olha para o futuro, para o momento em que a coisa funcionará sozinha e em que a vigilância poderá não ser mais que virtual, em que a disciplina, por conseguinte, tornar-se-á um hábito. Aqui dois exemplos que organizam a disciplina: a figura do exercício e a da escrita. No primeiro caso, tratando-se do exercício corporal, este é descrito como um adestramento do corpo, adestramento da habilidade, da marcha, da resistência, dos movimentos elementares, e isso segundo uma escala gradual. No segundo caso, para assumir global e permanentemente o corpo do indivíduo, a escrita vai ser um instrumento necessário. Inicialmente, para garantir a notação e registro de tudo o que acontece, de tudo o que o indivíduo faz, de tudo o que ele diz; depois, para transmitir a informação de baixo para cima, ao longo da escala hierárquica e, por fim, para poder tornar sempre acessível essa informação e assegurar assim o princípio da onivisibilidade. É a escrita como condição de funcionamento do princípio panóptico, base da disciplina.

3 - O poder disciplinar é isotópico ou tende a isotopia e isto representa várias coisas. Primeiro é que em um dispositivo disciplinar, cada elemento tem seu lugar bem determinado; ele tem seus elementos subordinados, tem seus elementos superordenados, como as patentes no exército. Na escola, a nítida distinção entre as diferentes classes de idade e, nas diferentes classes de idade, a posição de cada um na classe se constituem em exemplos desta propriedade do poder disciplinar.

Nesta forma de pensar o poder e seu funcionamento, os elementos constituintes dos sistemas disciplinares supõem uma fixação espacial, a extração ótima do tempo, a aplicação e a exploração das forças do corpo por uma regulamentação dos gestos, das atitudes e da atenção, a constituição de uma vigilância constante e de um poder punitivo imediato, enfim a organização de um poder regulamentar que, em si, em seu funcionamento é 
anônimo, não individual, resultando sempre em uma identificação das individualidades sujeitadas (idem, p. 89). Então, cabe interrogar: o que estava em questão na instituição geral dos dispositivos disciplinares? A acumulação dos homens, responde Foucault. Mas o que isto representa? Isto representaria uma ação paralela à acumulação dos capitais. E, para tornar possível a reprodução e expansão do capital, foi necessário realizar uma distribuição da força de trabalho presente em cada singularidade somática para maximizar a utilização possível dos homens, para tornar todos os indivíduos utilizáveis e elevar a rentabilidade do tempo do trabalho, aprendizagem, aperfeiçoamento, do tempo da aquisição dos saberes e das aptidões. Em forma de síntese, afirma

Essa tríplice função das técnicas de acumulação dos homens e das forças de trabalho, esse tríplice aspecto é, creio, a razão pela qual foram instituídos, testados, elaborados, aperfeiçoados os diversos dispositivos disciplinares. A extensão das disciplinas, seu deslocamento, sua migração, da sua função lateral para a função central e geral que exercem a partir do século XVIII, estão ligadas a essa acumulação dos homens e ao papel da acumulação dos homens na sociedade capitalista. (idem, p. 90)

Pensado nos termos de uma microfísica, o poder disciplinar encontra sua formalização mais acabada no Panopticon de Jeremy Bentham. Este modelo de funcionamento do poder disciplinar é tomado como uma forma para toda uma série de instituições (prisão, escolas, hospital, oficina, orfanato, fábrica,..), sendo um esquema, uma espécie de mecanismo que possibilita que o poder atinja o máximo de sua força. Trata-se de tornar a força do poder mais intensa, sua distribuição melhor, seu alvo de aplicação mais certo (idem, p. 92).

Esta forma do poder age, inclusive, nas instituições que não seguem rigorosamente este modelo, mas a ele se encontram 
diretamente ligado, como é o caso da família, por exemplo. Embora funcione segundo uma dinâmica mais próxima a do poder soberano, à família cabe desempenhar o papel de deliberar acerca do normal e do regular. Cabe a ela remeter aqueles classificados de anormais e irregulares às instituições construídas para lidar com a anormalidade ou irregularidade. É, pois, ao fim da operação desenvolvida no interior dessas máquinas a serviço da disciplina, que o indivíduo pode finalmente voltar a figurar na morfologia da família normalizada e normalizadora. Deste modo, embora o poder da família seja assemelhado ao poder soberano, esta para funcionar precisa estar em permanente articulação com as instituições caracterizadas pelo poder disciplinar, discreto, confiscador do tempo, contínuo e isotópico.

De modo sumário e geral, estes elementos contidos nas aulas de 1973/1974 ajudam a pensar o caminho do pensamento de Foucault acerca do poder e ajudam a reler os termos do "Vigiar e Punir". Auxilia igualmente a problematizar a crítica de que Foucault ao enfatizar as máquinas e engrenagens da sociedade moderna faz desaparecer o sujeito e sua capacidade de inventar e transformar a vida. Nestas aulas, ele não cessa de oferecer exemplos das ações humanas no interior das máquinas montadas. Neste caso, digno de nota é o fato de que as ações que reconhece e torna visível partem daqueles que a família e a ciência classificam de "sem razão". Os "despossuídos de juízo" também dissimulam e iludem os poderes a que são submetidos, forjando no interior dos asilos e hospitais psiquiátricos experiências inéditas e imprevistas. Deste modo, o reconhecimento das ações celulares destes indivíduos ajuda a rever a tese da existência de um "Foucault homicida", ainda que seja necessário reconhecer sua desconfiança frente ao homem e sua descrença no humanismo.

Em linhas gerais, temos aí uma espécie de esboço de uma teoria que reconhece um poder sobre a vida e de um poder da vida como desiguais e sempre desequilibrados. É esta diferença 
de potência que faz emergir determinados arranjos e é ela também que pode fazer aparecer arranjos surpreendentes e imprevistos. Ao reconhecer aquilo que, mais tarde, vai ser descrito e designado como biopoder - o poder sobre a vida e a biopolítica - a poder da vida, Foucault organiza suas reflexões para tornar compreensível o exame da sociedade moderna e as possibilidades de pensar o que ainda não fora pensado. É, pois, na companhia destas reflexões, tomadas como coordenadas gerais que procurei pensar três esquemas disciplinares a que os sujeitos e seus corpos são submetidos, com base em experiências bem precisas, como forma de trazer alguma empiricidade e para dar seguimento ao debate.

\section{Corpos Higienizados}

Nesta segunda parte, gostaria de trazer para o debate três cenas, extraídas de geografias particulares, sob registros distintos para dar a ver a presença da disciplina exercida sobre os corpos. Com isto, pretendo demonstrar a extensão da preocupação com os sujeitos e seus corpos, chamando atenção para instituições envolvidas e saberes mobilizados nos projetos de modelação que se pretendeu por em curso. Corpos entendidos em uma chave tripla, já que as ações remetem ora ao corpo-anatomia, corpo-neurologia e/ou corpo-vontade, isto é, nas três cenas pretendo retrabalhar a máxima da educação integral, esta espécie de saber estendido voltado para educar o homem do ponto de vista físico, intelectual e moral ${ }^{7}$.

A primeira cena remete ao exame de um discurso difundido pela ciência médica em manuais de Higiene. Explorei dois casos, para animar o debate. O primeiro foi escrito inicialmente em $1846^{8}$, tendo

${ }^{7}$ Uma reflexão mais detalhada sobre este concepção se encontra desenvolvida em Gondra, 2004.

${ }^{8}$ Hygiène des familles ou du perfectionnement physique et moral de l'homme, considéré particulièrement dans ses rapports avec l'éducation, et les besoins de la civilisation moderne. - Paris : Labé, 1846. - 2 vol.

Educ. e Filos. Uberlândia, v. 23, n 45, p. 65-100, jan./jun. 2009 
sido republicado em 1858, modificado e corrigido, intitulado "Tratado especial de higiene das famílias, em particular nas suas relações com o casamento, o físico, moral e as doenças hereditárias”. Seu autor, professor de clínica interna na Escola de Medicina de Lyon também é médico honorário de "L'Hotel Dieu", membro do Conselho de Higiene e de salubridade pública de Rhone e inspetor de trabalho das crianças nas manufaturas, dentre outras posições que ocupara.

No prefácio da segunda edição, Devay faz uma forte defesa da ciência que representa e que ajuda a legitimar e disseminar. Apoiado em autores diversos, como Leibnitz e Reveillé-Parise, defende a higiene como o mais belo ramo da árvore das ciências médicas, que pode produzir frutos abundantes. Ciência vasta, profunda e intimamente vinculada à sabedoria dos mais belos gênios da antiguidade grega. Para ele, a boa Higiene deveria possuir caráter preventivo e deveria recobrir diferentes aspectos da vida para poder funcionar como a ciência salutar que pretendia ser.

Os objetos a serem recobertos pela Higiene podem ser evidenciados na estrutura de quatro partes que o autor imprime ao livro e que se inicia com um texto de caráter programático, caracterizando os objetivos, aplicações, divisões e relações da Higiene com a civilização. Na segunda parte, o autor se ocupa da higiene da espécie humana, na terceira privilegia a higiene física e, na quarta parte, aborda a higiene moral e os modificadores morais. Tudo isto distribuído nas 765 páginas do manual.

Como se pode perceber, a doutrina da Higiene ao se ocupar da vida e da saúde configura-se como um saber vasto, procurando se representar como uma verdadeira ciência do social. Deste modo, isolar qualquer um dos elementos abordados pela Higiene supõe considerar o arco deste saber. Tendo isto em vista, vou fazer um comentário sumário sobre as representações do físico disseminadas no manual.

Cabe antecipar que, ao dedicar a terceira parte do tratado ao problema da higiene física, este mantém o tom geral do livro, pois o tratamento que dispensa a este tema vem presidido pelo princípio 
geral das vistas largas, como mecanismo para definir o estatuto da higiene como a ciência do social, que pensa o homem sob os pontos de vista físico, intelectual e moral.

A terceira parte do guia de higiene foi estruturada como se segue:

Tratado Especial de Higiene das Famílias - Estrutura da terceira parte

\begin{tabular}{|c|c|}
\hline \multicolumn{2}{|c|}{ Higiene Física } \\
\hline \multicolumn{2}{|c|}{ Seção I - Da atmosfera dos lugares e das habitações } \\
\hline \multirow{8}{*}{ Capítulo 1} & Do ar atmosférico \\
\hline & Da pressão atmosférica \\
\hline & Da pureza do ar \\
\hline & Do ar não renovado ou confinado \\
\hline & Apartamentos e quartos de dormir \\
\hline & Do ar viciado em virtude de algumas operações domésticas \\
\hline & Do ar viciado pelas emanações vegetais ou animais \\
\hline & $\begin{array}{l}\text { Do ar viciado pela emanações dos indivíduos vivos (infecção, } \\
\text { contágio) } \\
\text { Das doenças contagiosas }\end{array}$ \\
\hline \multirow{7}{*}{ Capítulo 2} & $\begin{array}{l}\text { Da qualidade do ar em função da temperatura e da hogrometria, } \\
\text { das estações do ano. } \\
\text { Das vicissitudes atmosféricas, influências metereológicas, } \\
\text { iluminação, eletricidade, etc. }\end{array}$ \\
\hline & Do ar frio e seco, frio e úmido (inverno) \\
\hline & Do ar seco e quente (calor, verão) \\
\hline & Do ar quente e úmido (começo da primavera e do outono) \\
\hline & Variações do ar e vicissitudes atmosféricas \\
\hline & Da luz, de sua influência higiênica \\
\hline & De algumas influências metereológicas e siderais \\
\hline \multirow{4}{*}{ Capítulo 3} & Das habitações - lugares, exposição \\
\hline & Do mefitismo das habitações \\
\hline & $\begin{array}{l}\text { Das habitações úmidas; da umidade considerada como uma das } \\
\text { causas gerais das doenças }\end{array}$ \\
\hline & $\begin{array}{l}\text { Do clima em geral, dos climas temperados, da Europa. Da escolha } \\
\text { do clima como meio profilático de certas afecções }\end{array}$ \\
\hline
\end{tabular}




\begin{tabular}{|c|c|}
\hline \multicolumn{2}{|c|}{ Seção II - dos Alimentos e Bebidas } \\
\hline Capítulo 1 & $\begin{array}{l}\text { Da alimentação considerada como reparadora e como fortificante. } \\
\text { Divisão dos alimentos vegetais (trigo, féculas, legumes e frutas). } \\
\text { Alimentos retirados do reino animal. Quadro sinóptico dos } \\
\text { alimentos }\end{array}$ \\
\hline Capítulo 2 & $\begin{array}{l}\text { Das bebidas em geral: da água sob o ponto de vista da higiene, } \\
\text { das características das boas águas. Abuso e perigo das bebidas } \\
\text { frias em algumas circunstâncias. Influência das boas águas sobre } \\
\text { a saúde das populações. Das bebidas fermentadas: do vinho, de } \\
\text { suas qualidades diversas, a cerveja e a cidra. }\end{array}$ \\
\hline Capítulo 3 & $\begin{array}{l}\text { Das bebidas alcoólicas espirituosas: aguardente }{ }^{9} \text {, licores fortes, } \\
\text { da embriagues, cafés, de suas influências. Das bebidas excitantes } \\
\text { não fermentadas: café, chás - suas vantagens e abusos. }\end{array}$ \\
\hline Capítulo 4 & $\begin{array}{l}\text { Da boa alimentação: o pão, a carne e o vinho - bases de uma boa } \\
\text { nutrição. Da variedade na alimentação, dos condimentos e do sal } \\
\text { dos alimentos. Da boa comida - seus abusos e perigos }\end{array}$ \\
\hline Capítulo 5 & $\begin{array}{l}\text { Regaras particulares de regime ainda não indicadas: da refeição, } \\
\text { de sua quantidade e ordem. Regras particulares do regime relativa } \\
\text { a certas circunstâncias da vida (estações, climas). Observações } \\
\text { sobre os utensílios e suas relações com a bromatologia. De alguns } \\
\text { alimentos perigosos. }\end{array}$ \\
\hline \multicolumn{2}{|c|}{$\begin{array}{l}\text { Seção III - Dos exercícios, repouso e das que se aplicam à superfície dos } \\
\text { corpos. Das roupas. }\end{array}$} \\
\hline Capítulo 1 & $\begin{array}{l}\text { Dos exercícios em geral. Exercícios ativos: o passeio, corrida, } \\
\text { jogos. Exercícios passivos: equitação, direção, navegação. } \\
\text { Exercícios raciocinados ou ginásticos - suas vantagens e seus } \\
\text { perigos. Da escolha de sua aplicação. Do repouso, sono ou } \\
\text { repouso completo. Higiene do sono. }\end{array}$ \\
\hline
\end{tabular}

${ }^{9}$ Uma tradução literal seria algo como "água da vida". 


\begin{tabular}{|c|c|}
\hline \multirow{6}{*}{ Capítulo 2} & $\begin{array}{l}\text { Das coisas que se aplicam à superfície dos corpos. Higiene da } \\
\text { pele, da limpeza, das fricções, massagens, abluções. Dos banhos, } \\
\text { banhos frios, banhos de mar, banhos quentes e mornos. Da } \\
\text { higiene da pele e de suas relações com outras funções. Higiene } \\
\text { das partes acessórias da pele: unhas, cabelos, pelos e dentes. }\end{array}$ \\
\hline & Das loções, dos banhos \\
\hline & Banhos frios, suas vantagens \\
\hline & Banhos de mar, seus efeitos fisiológicos e higiênicos \\
\hline & Banhos quentes, suas vantagens e seus abusos \\
\hline & $\begin{array}{l}\text { Relação da higiene da pele com outras funções da economia. } \\
\text { Higiene das produções epidérmicas (cabelos, unhas, dentes, barba) }\end{array}$ \\
\hline Capítulo 3 & $\begin{array}{l}\text { Considerações gerais sobre as vestimentas considerando a } \\
\text { civilização atual. Das roupas quentes, da flanela. Roupas } \\
\text { perigosas pela constrição: bonés, gravatas, espartilho, sapatos, } \\
\text { etc. Regras gerais aplicáveis a maneira de se vestir. }\end{array}$ \\
\hline \multicolumn{2}{|c|}{$\begin{array}{l}\text { Seção IV - dos modificadores que agem sobre a sensibilidade geral e sobre } \\
\text { alguns dos sentidos em particular }\end{array}$} \\
\hline Capítulo 1 & $\begin{array}{l}\text { Da higiene e da educação dos sentidos de forma geral. Do prazer } \\
\text { sob o ponto de vista da higiene: prazeres mórbidos e prazeres } \\
\text { úteis. Da direção dos prazeres para a felicidade aperfeiçoamento } \\
\text { do homem. Da dor física considerada em sua relação com a } \\
\text { higiene. Exemplos }\end{array}$ \\
\hline Capítulo 2 & $\begin{array}{l}\text { Higiene dos sentidos em particular. Do tato e do toque. Higiene } \\
\text { da visão: miopia, presbitia. Higiene da audição; da música sob o } \\
\text { ponto de vista da higiene. Higiene do órgão do gosto. Do sentido } \\
\text { do odor. }\end{array}$ \\
\hline Capítulo 3 & $\begin{array}{l}\text { Do sentido da volúpia. Do onanismo no caso das crianças } \\
\text { pequenas e no caso dos adolescentes. Efeitos físicos e morais. } \\
\text { Preceitos higiênicos. }\end{array}$ \\
\hline
\end{tabular}


Como podemos perceber, o tema do físico segue o programa partilhado pelos higienistas que se apropriam do modelo disseminado por Royer Collard, que distribui as ações da Higiene em torno de seis núcleos: circumfusa, applicata, ingesta, gesta, excreta e percepta 9 . Trata-se, portanto, de um modelo no qual se combinam e se articulam prescrições gerais acerca do ambiente natural, de suas relações com os corpos e suas funções vitais, organizando uma ciência para a promoção de ações regulares e calculadas sobre o corpo-anatomial fisiologia, corpo-neurologia e sobre o corpo-vontade.

Em linhas gerais este modelo é encontrado em outros manuais de higiene, como os de Becquerel e Riant, mas também em discursos médicos no Brasil, o que pode ser evidenciado tanto no programa de formação dos médicos, nas teses defendidas e nos manuais e compêndios que médicos dos trópicos redigem ou traduzem. Para ficar apenas em um exemplo, procurei observar sinais deste programa higiênico em outro manual. A seleção incidiu sobre um dos livros escritos por Afrânio Peixoto, no qual aborda a educação da mulher. Neste caso, evitei trabalhar com os dois volumes de seu tratado de higiene, no qual a articulação com o modelo geral da Higiene seria mais esperada.

Afrânio Peixoto, como sabemos, foi um médico formado na Bahia e que tem uma vasta produção intelectual, em diversos domínios, como a medicina, jornalismo, política, administração pública, magistério, poesia, teatro, biografia, história e romance, por exemplo. De acordo com Lopes (2002), chegou a produzir 141 títulos e a tiragem total de suas 90 obras impressas, algumas com várias edições, alcançou a marca de 599.200 exemplares $^{10}$. Desta vasta produção, me detive em apenas um de seus livros, intitulado “A educação da mulher", de 1936.

Já no prefácio, prepara os leitores para o que vão encontrar,

\footnotetext{
${ }^{9}$ Para um maior detalhamento deste modelo, cf. GONDRA, 2004.

${ }^{10}$ Para saber mais a respeito da trajetória de Afrânio Peixoto, cf. ROCHA, 2002.
} 
classificando seu livro como um ensaio de propaganda e justificativa da educação feminina, apoiado em documentação anatômica, fisiológica, psicológica e social como forma de rebater os "a priori" e as resistências insensatas dos misoneistas. ${ }^{11}$ Forma de rebater que vem apoiada em uma história que procura descrever "o que foi" a educação da mulher e "o que deve ser". Estas são precisamente as duas partes que estruturam o livro.

$\mathrm{Na}$ primeira parte, procede a um inventário do que foi a educação feminina junto aos "nossos selvagens", mas também junto aos asiáticos, indus, chineses, árabes, gregos e romanos para, em seguida, manter o tom de panorama, percorrendo a idade média, renascimento, para se deter em alguns casos exemplares dos séculos XVIII e XIX, com ênfase na experiência européia, particularmente na francesa.

Na parte em que joga o jogo da prescrição, aproxima-se da tese da educação integral, apoiando-se fortemente no exame da anatomia, fisiologia e problemas sociais associados aos dois sexos, como é o caso da diversidade anatômica dos sexos, das variações antropológicas, do crânio e encéfalo. Apóia-se igualmente na psicologia para analisar as diferenças e os processos mentais em homens e mulheres. Sua defesa da participação da mulher na vida social também se encontra associada ao exame da relação da mulher com o trabalho extra-doméstico, sobretudo o da operária. Neste caso, a inserção da mulher como força de trabalho vem acoplada à dimensão moralizadora do trabalho.

Ao se deterno problema da educação física, opera com o registro de que a restrição feita à educação das mulheres foi inventada com o advento do cristianismo. Segundo ele, os espartanos misturavam as raparigas aos rapazes para que elas se desenvolvessem, pudessem ser fortes, sadias e resistentes aos trabalhos da maternidade. Nesta tradição, o banho frio no rio e as vestes sumárias endureciam o corpo

${ }^{11}$ Aversão a tudo o que é novo.

Educ. e Filos. Uberlândia, v. 23, n 45, p. 65-100, jan./jun. 2009 
e o faziam resistente às intempéries. Do mesmo modo, a dança era uma instituição em Atenas, presente em todas as solenidades, tida como atividade intermediária entre a música e ginástica. Para ele, o cristianismo ao privilegiar o céu, desprezou o corpo. No caso feminino, selou, zelosamente, seu destino ao interior das roupas e do lar. Para sustentar esta verdade, apresenta posições de vários santos. Para São Jerônimo, o banho deveria ser inteiramente proibido às meninas, fosse pelo pecado, fosse pela sensualidade que poderia fazer despertar. Santa Silvia e Santa Oportuna desprezaram os cuidados com o corpo, cultivando até a imundície para poder agradar a Deus. São Crisóstomo assinalara que era o demônio quem dançava nos bailes. Por fim, para dar ainda mais credibilidade ao seu discurso, traz o testemunho pessoal no momento em que atuou como diretor de instrução pública, lembrando que muitos pais encaminharam protestos indignados contra a ginástica escolar, alegando que eles não educavam as filhas para serem atletas.

No entanto, a história de Peixoto é também a história do progresso, de uma civilização que se aperfeiçoa, que evolui. Para manter este tom, recolhe exemplos que atestam que os tempos estavam melhorando. Para tanto, faz referência ao caso da Maison de Saint Cyr, com a experiência da Mme de Maintenon na educação de meninas. Nesta instituição, o recreio era destinado ao pulo, dança, corrida, jogo de barra e outros exercícios que estimulassem o crescimento. Segue com os exemplos de Mme de Saussure, Spencer e Sócrates. Por fim, oferece o exemplo dos países nórdicos e anglosaxões como prova de que as coisas mudavam, progrediam. De acordo a descrição do médico baiano, naqueles países, as mulheres eram mais altas, fortes e mais capazes física e mentalmente, pois os exercícios esportivos como o tênis, beisebol, voleibol, natação, golfe e outros queimavam gorduras impróprias. Tais exercícios, ao proporcionar músculos tensos e desenvolvimento da ossatura, favoreciam o predomínio do tórax sobre a bacia, reduzindo as ancas, dilatando o peito, dando aos movimentos a ação e, ao pensamento, 
uma decisão e uma eficácia que aproximava a mulher do homem. Tudo isto concorria para desfazer as diferenças milenares que a funesta educação especializada dos sexos havia indevidamente posta ente eles, afirma Peixoto (1936, p. 178).

Mantendo-se nesta chave de leitura, Afrânio Peixoto faz questão de assinalar os proveitos dos exercícios físicos "sobre e para todo o corpo": no sistema ósseo, muscular, na circulação, respiração, nas funções nervosas, no trabalho, desenvolvimento intelectual e no temperamento da vontade e do caráter.

Localizado no interior do discurso médico-higiênico, o médico brasileiro também faz circular e legitima o princípio da moderação, que deveria guiar toda conduta humana. Tal fundamento também se encontra rebatido nas prescrições relativas aos exercícios corporais. Para ele, a máxima de Juvenal de mens sana in corpore sano não deveria implicar em abuso, fadiga, atletismo extranormal e simultaneidade de esforço físico e esforço mental. Com esta observação, assume a moderação como fundamento das ações humanas, cujas regras deveriam ser extraídas das verdades que a ciência médica oferecia aos homens e às instituições voltadas para a formação humana. No jogo proposto, havia de se considerar as condições de saúde de cada um, as idades da vida, menstruação, gestação, aleitamento, trabalho e tempo de repouso. Como se pode ver, o programa se ajusta ao modelo geral médico-higiênico, ainda que, neste caso, se deva sublinhar a função do mesmo na defesa da educação feminina e da presença obrigatória dos exercícios físicos para bem formar a mulher para o trabalho e maternidade. Em tom de resumo e conclusão, o professor e higienista afirma:

A educação física da mulher lhe é tanto, se não mais necessária do que ao homem: uma longa servidão reclusa e às vezes inativa [...] precisa ser compensada, para lhes ir sendo restituído o que perderam. Muito de sua exigüidade do corpo e de forças vem dessa atávica e milenar inatividade e submissão passiva.

Educ. e Filos. Uberlândia, v. 23, n 45, p. 65-100, jan./jun. 2009. 
Hábitos nocivos chegaram a lhe modificar a fisiologia: ao tempo do colete ou espartilho, armadura de barbatanas, de aço e de lona, dizia-se que elas tinham um tipo especial de respiração, 'costosuperior', enquanto a do homem era 'costo-inferior'... Pudera! Obrigadas, pelo estojo em que se metiam, podiam apenas mover a parte superior do tórax, de onde o arfar do colo, tão gabado pelos poetas... sem colete, uma mulher respira como os homens, movendo as costelas inferiores e o diafragma, de onde o movimento do ventre... Não há tipo respiratório especial aos sexos....

[...] A educação física amadurece mais cedo os indivíduos para a vida, e as jovens mães pagam pesado tributo por falta de desenvolvimento adequado, os filhos delas consoantemente. Aureliano Portugal atribuía parte de nossa grande morti-natalidade infantil à precocidade dos casamentos, sobretudo das mulheres [...] não desenvolvidas pela educação física. (p. 181-182)

Como podemos observar, a defesa da educação feminina se faz de modo a atender os princípios gerais da racionalidade médica, que pretende tornar a mulher educada e produtiva, nas casas e no trabalho. Contudo, o ajustamento da mulher a este novo tempo e novas funções que lhes são reservadas pelos "apóstolos do progresso", pelos "missionários da civilização" só seria atingido caso fosse educada e educada integralmente.

\section{Corpos Internados}

De uma racionalidade difundida nos dois lados do Atlântico, proponho um deslocamento para pensar uma experiência inglesa, na qual se articulam a racionalidade médico-higiênica aplicada à educação feminina. Trata-se, neste caso, de uma encenação extraída de um romance inglês. Aqui não é possível entrar nos debates do campo da teoria literária e dos limites e possibilidades da literatura 
como fonte histórica, sobretudo nos textos de caráter autobiográfico. Sabemos que teorizar as fontes se constitui em uma exigência de nosso ofício, mas os limites desta exposição permitem apenas recolocar que o uso da literatura como fonte para a história deve ser enfrentado como um problema que possui contornos próprios e exige investimento intelectual nesta direção. Regra que, de resto, deveria pautar a relação com qualquer corpus documental. Com esta espécie de advertência preliminar, quero assinalar que trabalhei com o livro da Charlotte Brontë ${ }^{12}$, intitulado Jane Eyre.

Neste romance, a escritora britânica Charlotte Brontë (1816-1855) narra a história de Jane Eyre, por meio de um texto composto por três núcleos: o tempo da casa, da escola e do trabalho. Uma das pistas do caráter autobiográfico deste livro diz respeito à narrativa desenvolvida em primeira pessoa por uma inglesa cuja biografia apresenta traços semelhantes ao da personagem central, pois, do mesmo modo que Jane Eyre, Charlotte Brontë também ficou órfã, passou pela experiência do internato feminino e exerceu as funções de preceptora e professora na Inglaterra no século XIX. Ao lado do testemunho deste "eu", que romanceia sua existência e narra sua própria vida por meio desta estratégia, há também outra evidência autobiográfica, que decorre do processo que à época se procurou mover contra a autora. Em defesa, ela precisou escrever uma carta desculpando-se publicamente pela descrição que fez de uma escola inglesa. $\mathrm{O}$ atrito se deu devido à descrição literária de Brontë sobre as péssimas condições existentes na Lowood School, escola ficcional inspirada no Clergy Daughters' School, de Cowan Bridge, em Lancashire. Além disso, a escritora se valeu da figura do fundador e diretor dessa instituição, o reverendo William Carus-Wilson, como inspiração para o personagem de ficção $\mathrm{Mr}$. Brocklehurst, o autocrático e agressivo diretor de Lowood. Segundo

\footnotetext{
${ }^{12}$ Charlotte Brontë nasceu em 1816 em Yorkshire e, junto com suas irmãs Emily e Anne, formou um dos trios mais importantes da literatura inglesa vitoriana.
}

Educ. e Filos. Uberlândia, v. 23, n 45, p. 65-100, jan./jun. 2009. 
as cartas de Charlotte, Carus-Wilson se enfureceu ao ler a descrição de Brocklehurst em "Jane Eyre", quando a obra foi publicada em 1847, e procurou conselhos legais para iniciar uma ação contra a escritora. A ação judicial foi evitada apenas porque Brontë escreveu uma carta desculpando-se publicamente e admitindo ter exagerado na composição da personalidade do diretor.

Em que nos interessa esta narrativa? Ela nos interessa na medida em que pode nos ajudar a pensar a história de muitas crianças órfãs. No caso, trata-se de uma menina que, se encontrando "só no mundo", é entregue aos cuidados da tia que a trata de modo muito distinto dos seus filhos naturais. Para ela, a menina possuía um conjunto de vícios que não seriam corrigidos com o auxílio da educação doméstica, o que fica evidenciado nas lembranças de Jane Eyre:

Minha tia, a Sra. Reed, banira-me de sua convivência, consideravame socialmente inapresentável, menina cheia de defeitos, que teria de manter a boca fechada, o mais longe possível, até que soubesse falar e comportar-se com delicadeza.

Descrita como incorrigível, seu destino é o internato feminino. Instituição total, para empregar o termo de Erwin Goffman (2001). Lugar de guarda de indivíduos e do controle integral de seu modo de vida, o internato deve agir de modo discreto e contínuo de modo a retificar a menina, sobretudo do ponto de vista moral. No entanto, para promover uma retificação efetiva, as ações também procuram atingir o físico e o intelecto, por intermédio de um conjunto de exercícios, por meio dos quais se pretendia obter uma espécie de ascese, de elevação. Para tanto, a rotina da instituição procura combinar trabalho intelectual, habilidades manuais e um conjunto de ações voltadas para a disciplinarização de seus internos.

A rotina tem início com o despertar, a higiene pessoal, a reza, refeições regradas e ajustamento geral ao código do internato. Qualquer desvio ou anomalia deveria ser submetido ao castigo 
exemplar, de modo que a punição funcionasse como elixir para evitar que as demais incorressem na mesma falta. Um único exemplo. Ao serem perfiladas para a vistoria regular do diretor, Jane Eyre deixa cair sua ardósia. Neste momento, todos se voltam para ela em um movimento único e o diretor a classifica como "Menina descuidada!", punindo-a exemplarmente:

Ponham-na ali, de pé, naquele banco - ordenou o Sr. Brocklehurst e ouçam o que eu vou dizer, em proveito do colégio. Aparentemente essa menina é uma criança, sem nada que denuncie que o Demônio mora nela, como uma ovelha negra, transfugazinha do Senhor! Em guarda contra ela! Observai-a, professoras, castigando-lhe o corpo, para redimir-lhe a alma! Essa menina é uma mentirosa! (p. 40)

A cisão entre corpo e alma funciona como uma inteligência que liga as duas partes, de modo a justificar medidas empregadas e os efeitos que delas se esperava. Neste caso, a penalidade incide sobre o corpo, embora no limite, visasse dobrar a vontade do infrator. Agindo sobre a individualidade, a direção do internato pretende atingir a totalidade, multiplicando a força do poder da instituição. Creio que estamos frente a uma máquina exemplar do poder disciplinar, no modo como faz amplificar o poder e os efeitos de individualização esperados das instituições, algo evidenciável no modo como a microfísica do poder funciona efetivamente, isto é, no modo como os sujeitos podem de fato agir.

\section{Corpos Regulamentados}

A terceira cena nos remete a um caso brasileiro, mais particularmente nos remete à modelos institucionais imaginados para serem postos em funcionamento na cidade do Rio de Janeiro no século XIX. Neste caso, trata-se de experiências de internatos voltados para a educação de cegos e surdos-mudos. Procurei dar

Educ. e Filos. Uberlândia, v. 23, n 45, p. 65-100, jan./jun. 2009 
a ver este tipo de engrenagem tomando por base regulamentos e regimentos destas instituições. Não se trata, pois, de observar a engrenagem em seu funcionamento, mas em seus condicionamentos como forma de demonstrar uma vez mais o alargamento da razão como substrato exigido para a institucionalização geral promovida nos tempos modernos ${ }^{13}$.

No Brasil, o desafio de educar cegos e surdos-mudos ganhou impulso em meados do século XIX, quando o poder público se voltou para este segmento da população, reconhecendo a necessidade de intervenções regulares e calculadas sobre esta diferença.

No que se refere aos institutos especiais, o primeiro a ser criado foi o Imperial Instituto dos Meninos Cegos, por intermédio do Decreto Imperial n. ${ }^{\circ} 1.428$, de 12 de setembro de 1854 , tendo sido inaugurado, solenemente, no dia 17 de setembro do mesmo ano, na presença do Imperador, da Imperatriz e de todo o Ministério.

Três anos depois de criado o Instituto dos Cegos, o Estado passa a subvencionar o Instituto dos Surdos-Mudos, como consta na Lei orçamentária 939 de 26 de setembro de 1857. Esta lei previa a subvenção anual de 5 contos de reis e mais dez pensões de $500 \$ 000$ cada uma em favor dos surdos-mudos pobres que nos termos do Regulamento interno do Instituto fossem aceitos pelo diretor e comissão fiscalizadora e aprovados pelo Governo. Como se pode ver o traço assistencial era mais uma vez empregado para justificar uma ação do Estado. No caso, o apoio a uma iniciativa privada, de um estrangeiro surdo, o francês, Hernest Huet e sua esposa. No entanto, o apoio de "homens distintos" à iniciativa do francês teria tido início após o quarto mês de funcionamento. De acordo com Couto Ferraz, ministro responsável pela matéria da instrução, considerando o zelo, inteligência, perseverança e apreciando o rápido progresso dos discípulos do Sr. Huet no primeiro quadrimestre de 1855, oito

${ }^{13}$ A respeito do esforço de educação elementar, secundária e superior no século XIX no Brasil, cf. GONDRA \& SCHUELER (no prelo). 
homens da "boa sociedade" (Marqueses de Abrantes, Monte Alegre e de Olinda, Eusébio de Queirós, o abade do Mosteiro de São Bento, o prior do Convento do Carmo, Dr. Manoel Pacheco da Silva e o cônego Joaquim Caetano Fernandes Pinheiro) formaram uma comissão promotora para animar o funcionamento do Instituto dos Surdos.

A ação implicou na chegada de dois novos alunos no mês de maio. A manutenção dos mesmos decorria das pensões pagas pelo Mosteiro de São Bento e Convento do Carmo. Estas duas instituições também assumiram o aluguel do Instituto quando ele saiu das dependências do colégio Vassimon, onde suas atividades tiveram início. Em dezembro de 1856 o Instituto somava sete alunos, sendo 4 meninos e 3 meninas, procedentes de MG (2), SP (1) e quatro da própria Corte. Apenas os de MG e SP eram mantidos pelas famílias. O recurso para manutenção dos demais decorria do consórcio duradouro estabelecido com as ordens católicas e de recursos advindos de atividades do Teatro São Januário, Teatro Lírico e de renda arrecadada nos bailes de carnaval deste Teatro destinadas pelo Governo para o Instituto dos Surdos-mudos e Recolhimento de Santa Teresa.

Decorridos dez anos de subvenção oficial, o Regulamento Provisório de 19 de dezembro de 1867, elaborado na gestão do ministro José Joaquim Fernandes Torres, estabelece que a partir daquela data o Instituto dos Surdos-Mudos passa a ser uma instituição pública, oficial. Devia ser gratuita apenas para os comprovadamente pobres, até o limite de 16. Dentre os pobres, dar-se-ia preferência para os órfãos, filhos de militares do exército e da armada e dos empregados públicos que tivessem prestado serviços importantes ao Estado, levando-se em conta o critério da antiguidade para efeito de desempate. Os demais seriam incorporados na condição de pensionistas.

Desde o início o Instituto previa a admissão de alunos dos dois sexos, ficando os surdos sob os cuidados do Sr. Huet e as meninas sob os cuidados de sua esposa. $\mathrm{O}$ acesso, no entanto, se encontrava na dependência do atendimento a um conjunto de exigências, semelhante às do Instituto dos Cegos, sendo impedida a matricula 
aos considerados "idiotas". No que se refere tempo de duração do curso e idade, o regulamento de 1867 previa curso de cinco anos, com possibilidade de prorrogação, para alunos entre 9 e 16 anos.

Com isto cabe indagar: qual o impacto desta instituição no atendimento desta fração da sociedade? Sobre esta questão merece destaque o debate acerca da pouca quantidade de alunos no Instituto. Tobias Leite, diretor do Instituto em sua nova fase, procura identificar, em 1871, as causas que levavam ao não preenchimento, inclusive, das 16 vagas gratuitas destinadas aos pensionistas do Estado. Nesta direção, articula três fatores. O primeiro seria uma dupla ignorância, a da existência do Instituto e a de que o surdomudo era tão susceptível de educação como os falantes. Atribui, em segundo lugar, ao problema social, pois, segundo ele, os surdosmudos eram, na quase totalidade, filhos de "famílias indigentes ou de tão poucos meios" que não podiam vencer a distância que os separavam da Corte. Por fim, considera outro fator cultural que fazia com que "os pais desses infelizes", acometidos por uma "mal entendida compaixão", preferissem "vê-los junto a si, embora mergulhados em hedionda ignorância".

$\mathrm{Na}$ seqüência de seu relatório, o diretor explorava outro aspecto que ajudava a entender a baixa procura pelo Instituto. Em sua ótica, se disseminara a crença errônea de que o Brasil possuía poucos "infelizes privados da palavra". Ainda que contasse com deficientíssimas informações oficiais, o dirigente procurou desfazer esta verdade ao apresentar um quadro do número de surdos-mudos existentes em 15 Províncias. Admitindo-se a precariedade da informação, mesmo assim, imaginamos que ela oferece alguma visibilidade aos surdos-mudos do século XIX. Deste modo, apoiado na estadística, Dr. Tobias Leite reconhece a existência de 282 meninos e 186 meninas menores de 14 anos distribuídos no território nacional e 924 surdos-mudos maiores de 14 anos, totalizando uma população de 1392 indivíduos.

Com esta demografia dos surdos, ainda que reconhecidamente 
deficiente, o diretor visibiliza a população dispersa no território nacional. Ao localizá-la, o diretor procura afirmar a idéia de que o Brasil possuía surdos em quantidade e, deste modo, reforça suas preocupações com o reduzido número de alunos no Instituto. Tratavase, na perspectiva do diretor de, efetivamente, combater a ignorância e mobilizar os agentes sociais para que o Instituto ampliasse o raio de sua ação e cumprisse seu papel na institucionalização desta diferença. Não desejava uma expansão ilimitada, o que fica claro quando assinala não pretender que os 468 surdos-mudos menores de 14 anos fossem para o Instituto e cujos nomes, filiação e residência constavam nas informações que possuía. Afirmava apenas que o orçamento do estabelecimento admitia incorporar aos treze existentes, "mais quinze ou vinte infelizes dessas centenas que por aí vegetam nas mais tristes condições", como registrou.

No caso do Instituto Imperial dos Meninos Cegos, seu regulamento provisório estabelecia que aos alunos fosse oferecida instrução primária, educação moral e religiosa, ensino de música, ensino de alguns ramos da instrução secundária e ofícios fabris, seguindo o método Braille, adotado no Instituto similar de Paris, em um curso de oito anos, havendo a possibilidade de uma prorrogação por mais dois anos.

O Instituto pretendia abrigar meninos, até o máximo de 30 nos três primeiros anos, sendo que até 10 poderiam ser atendidos gratuitamente, desde que reconhecidamente pobres. A estes, o governo forneceria sustento, vestuário e curativo. A indigência deveria ser atestada pelo pároco e duas outras autoridades do "lugar de residência" do menino cego. Os demais precisavam pagar pensão de $400 \$ 000$ anuais e $200 \$ 000$ no ingresso. No entanto, ter ou não ter dinheiro não se constituía na única exigência para o ingresso. Os meninos também deveriam apresentar certidão de batismo ou documento que provasse idade entre 6 e 14 anos e atestado médico que comprovasse cegueira total. Além disto, deveriam possuir atestado de vacina "com bom resultado", não sofrer "enfermidade 
contagiosa" e não poderiam ser escravos.

Aqui vale uma nota curiosa. Embora presente na designação do Instituto, reforçada na previsão de pessoal (pois não se prevê contratação de professora, nem inspetora e camareira), o Instituto recebe meninas, como assinalado nos relatórios ministeriais. Em 1870, o Comissário do Governo, o Barão do Bom Retiro, ministro que decretara a criação do Instituto, redige relatório endereçado a João Alfredo Correa de Oliveira, novo ministro dos Negócios do Império, no qual destaca os problemas e avanços da instituição que ele ajudara a criar. Neste momento, o que mais mobilizava o Comissário era a questão do espaço. Ainda que reconhecesse as qualidades do edifício onde o Instituto funcionava, julgava que ele era inadequado para atender 30 alunos do sexo masculino e feminino em regime de internato, supondo as necessidades de dormitórios, refeitório e rouparia, por exemplo.

Reconhecer a presença de meninas se constitui em um pequeno detalhe que fortalece o princípio de que não devemos nos contentar com a verdade de uma única fonte posto que, neste caso, a confiar exclusivamente no Regulamento de 1854, ficaríamos com a ilusão (ou a verdade) de que o Imperial Instituto dos Meninos Cegos teria funcionado como um internato masculino. Para se ter uma idéia, dos 16 internos de $1855^{14}$, três eram meninas, conforme consta no relatório ministerial.

Em 1888, o ministro, apoiado no relatório do novo Comissário, Dr. Joaquim Antonio Fernandes de Oliveira (que substituiu o falecido Dr. Antonio Candido da Cunha Leitão) atesta a existência de 47 alunos, sendo 30 do sexo masculino e 17 do feminino. A presença das meninas repõe a questão do espaço, aparecendo igualmente rebatida na questão do pessoal e dos saberes a serem difundidos nesta escola especial.

\footnotetext{
144 eram provenientes da própria Corte, 6 da Província do Rio de Janeiro, 3 da
} Bahia e 1 do Ceará, São Paulo e Santa Catarina. 
$\mathrm{O}$ que deveria ocorrer com os cegos pobres, decorrido os 8 ou 10 anos no Instituto? O governo a eles daria o destino que julgasse conveniente ou seriam contratados como "repetidores" no próprio Instituto, desde que tivesse reconhecido talento, estudo e procedimento compatível com o magistério. Destino que precisava ser regulado, o que ajuda a compreender a preocupação recorrente com os saberes disseminados e com as oficinas que o Instituto deveria oferecer, como as de artes mecânicas, marcenaria, afinador de piano e sapataria, por exemplo.

Como se pode perceber, o princípio da escolarização foi pouco a pouco se capilarizando, afirmando a escola como agência necessária para a elite que desejava modernizar e civilizar a população como um todo. É esta vontade que ajuda a compreender a criação de engrenagens voltadas para uma população que durante muito tempo sequer foi considerada, como a dos cegos e surdos-mudos. Nestas instituições, o programa elaborado para a escola primária geral sofre poucas alterações, salvo nos reparos metodológicos. Mantém-se igualmente inalterada a perspectiva da educação escolar oferecida à população pobre, seja ela a dos arsenais, seja a das escolas especiais. Para esta população a combinatória de uma instrução rala e rudimentos de ofícios manuais seriam suficientes para assegurar existência decente e ordem civilizada, como não cansaram de repetir os homens ilustrados do Império brasileiro, apoiados na autoridade das racionalidades a que recorrem. ${ }^{15}$

\section{Corpos Civilizados, Corpos Disciplinados}

Por fim, como articular estas cenas tão díspares, processadas em contingências tão específicas? Este jogo de rebatimento múltiplo a que recorri sugere que estamos efetivamente frente a um largo

\footnotetext{
${ }^{15}$ Para um maior detalhamento das formas escolares criadas no século XIX, cf. GONDRA \& SCHUELER (no prelo).
}

Educ. e Filos. Uberlândia, v. 23, n 45, p. 65-100, jan./jun. 2009. 
projeto de modelação que se pôs em curso e que foi acentuado a partir do século XVIII. Neste agenciamento geral, pode-se evidenciar uma espécie de redescoberta da plasticidade da sociedade e dos homens. Aderido a esta verdade, homens e mulheres letrados, inscritos em domínios diversos, como a política, religião, medicina e literatura, por exemplo, não cessaram de acionar dispositivos para promover um enquadramento geral dos sujeitos e de seus corpos, fossem órfãos, cegos ou surdos-mudos. Neste novo agenciamento, o que aparece como substrato mais profundo se refere à crença no império da razão, condição para transformar a sociedade, descendo, quando possível e necessário, ao interior dos corpos. Invadindo os corpos, conhecendo seu funcionamento microscópico, construindo uma ciência deste interior; os homens e mulheres da ciência organizam um repertório que buscou legitimar ações gerais junto aos indivíduos, ligando o que antes não se encontrava ligado, conectando medidas globais com intervenções celulares.

Plásticos, sociedade e sujeitos deveriam ser submetidos ao saber que sobre eles se produziu em nome de uma ordem racionalizada. Neste desafio, as diferenças passaram a ser classificadas ou como naturais ou como desvios ou anomalias. Visto como natureza, nada podia ser feito para alterar os desequilíbrios e desigualdades que fabricavam determinadas diferenças. Como desvio ou anomalia, a diferença precisava ser enfrentada, combatida, normalizada.

Neste projeto, o que se encontrava posto era a vontade de civilizar, afastando tudo o que pudesse estar associado às vontades próprias e às culturas específicas. Neste jogo ambicioso, novos desvios, lutas inesperadas, circuitos interrompidos, transformações imprevistas, manutenções silenciosas também estiveram presentes, demonstrando que a vontade de governar, com todo o aparato produzido para legitimar a violência desta vontade, não conseguiu eliminar a potência da vida e tudo que ela torna possível, inclusive na esfera de saberes clássicos, como a Higiene. Potência que também se manifesta no interior das instituições totais, como os internatos para 
aqueles que foram deixados sós e para os que se viram privado do funcionamento de algum órgão.

Potência que também se manifesta em domínios e experiências diversas, pois nosso presente, como os outros, se encontra organizado por forças que flutuam, se deslocam e que, portanto, podem fazer emergir novos ordenamentos, fruto de agenciamentos que não é possível antecipar e predizer com toda a certeza. Ouso finalizar, retomando o modo como Foucault encerra "Vigiar e punir", peça importante para aqueles que o acusam de homicida. No entanto, curiosamente, o livro é finalizado com um reconhecimento da ação humana, das batalhas travadas, pois, para Foucault, nesta humanidade central e centralizada, efeito e instrumento de complexas relações de poder, corpos e forças submetidos por múltiplos dispositivos de 'encarceramento, objetos para discursos que são eles mesmos elementos dessa estratégia, temos que ouvir o ronco surdo da batalha. Creio que podemos e devemos realizar este exercício de audição.

\section{Referências}

BRONTË, Charlotte. O professor. São Paulo: Global, 1983. . Jane Eyre. Rio de Janeiro: Ediouro, 1971.

COSTA, Jurandir F. Ordem médica e norma familiar. Rio de Janeiro: Graal, 1979.

DEVAY, Francis. Traité special d hygiène des familles. Paris: Labè, 1858.

ERIBON, Didier . Michel Foucault. São Paulo: Companhia das Letras, 1990.

.Michel Foucault e seus contemporâneos. Rio de Janeiro: Jorge Zahar, 1996. 
FOUCAULT, Michel. Vigiar e punir - história da violência nas prisões. Petrópolis: Vozes, 1991.

. Resumo dos cursos do Collège de France. Rio de Janeiro: Jorge Zahar, 1997.

. Microfísica do poder. $7^{\mathrm{a}}$ edição. Rio de Janeiro: Graal, 1998.

Ditos \& Escritos I (Problematização do sujeito: psicologia, psiquiatria e psicanálise). Rio de Janeiro: Forense, 1999.

. Em defesa da sociedade. São Paulo: Martins Fontes, 1999.

.Ditos \& Escritos II. Rio de Janeiro: Forense, 2000.

. Ditos \& Escritos III (Estética: literatura e pintura, música e cinema). Rio de Janeiro: Forense, 2001.

. Ditos \& Escritos IV (Estratégia, poder-saber). Rio de Janeiro: Forense, 2003.

. Ditos \& Escritos $V$ (Ética, sexualidade, política). Rio de Janeiro: Forense, 2004.

. Os anormais. São Paulo: Martins Fontes, 2002.

. A hermenêutica do sujeito. São Paulo: Martins Fontes, 2004.

. O poder psiquiátrico. São Paulo: Martins Fontes, 2006.

FRANCHE, Dominique et al. Au risque de Foucault. Paris: Éditions du Centre Pompidou, 1997.

GOFFMAN, Erving. Manicômios, prisões e conventos. $7^{\mathrm{a}}$ ed. São Paulo: Editora Perspectiva, 2001.

Educ. e Filos. Uberlândia, v. 23, n 45, p. 65-100, jan./jun. 2009. 
GONDRA, José. Artes de civilizar. Rio de Janeiro: Eduerj, 2004.

. Paul-Michel Foucault - uma caixa de ferramentas para a história da educação? In: FARIA FILHO, Luciano (org.). Pensadores sociais e história da educação. Belo Horizonte: Autentica, 2005.

GONDRA, José \& KOHAN, Walter (orgs.) Foucault 80 anos. Belo Horizonte: Autentica, 2006.

GONDRA, José \& SCHUELER, Alessandra. Educação, poder e sociedade no Império brasileiro. São Paulo: Cortez, (no prelo)

HABERMAS, Jurgen. O discurso filosófico da modernidade. São Paulo: Martins Fontes, 2004.

LAGRANGE, Jacques. Situação do curso. In FOUCAULT, M.. $O$ poder psiquiátrico. Trad. Eduardo Brandão. São Paulo: Martins Fontes, 2006.

LOPES, Eliane. Afrânio Peixoto. In: FAVERO \& BRITTO. Dicionário de educadores no Brasil. Rio de Janeiro: EdUFRJ, 2002.

MACHADO, Roberto et al. Danação da norma. Rio de Janeiro: Graal, 1978.

. (org) Microfisica do poder. Rio de Janeiro: Graal, 1979.

MENDONÇA, Lígia. Dando os primeiros passos na oficina de Foucault. UERJ: PROPEd, 2007. (mimeo).

MERQUIOR, José Guilherme. Michel Foucault ou o niilismo de cátedra. Rio de Janeiro: Nova Fronteira, 1986.

O'BRIEN, Patricia. A História da cultura de Michel Foucault. In HUNT, Lynn. A nova História cultural. São Paulo: Martins Fontes, 1995.

Educ. e Filos. Uberlândia, v. 23, n 45, p. 65-100, jan./jun. 2009. 
O'FARREL, Clare. Foucault - historian or philosofer? London: McMillan, 1989.

PAIVA, Fernanda. Sobre o pensamento médico-higienista oitocentista e a escolarização: condições de possibilidade para o engendramento do campo da educação física no Brasil. Tese (Doutorado em Educação) - Universidade Federal de Minas Gerais. 2003.

PEIXOTO, Julio Afrânio. A educação da mulher. São Paulo: Companhia Editora Nacional, 1936.

RAGO, Margareth. Foucault um pensamento desconcertante - o efeito Foucault na historiografia brasileira. Tempo Social. USP: São Paulo, 7(1-2): 67-82, 1995.

RAGO, Margareth, ORLANDI, Luiz \& VEIGA-NETO, Alfredo (orgs.). Imagens de Foucault e Deleuze - ressonâncias nietzschianas. Rio de Janeiro: DP\&A, 2002.

RAGO, Margareth \& VEIGA-NETO, Alfredo (orgs.). Figuras de Foucault. Belo Horizonte: Autentica, 2006.

REVEL, Judith. Nas origens do biopolítico: de "Vigiar e punir" ao pensamento da atualidade. In: GONDRA, José \& KOHAN, Walter (orgs.) Foucault 80 anos. Belo Horizonte: Autentica, 2006.

RIBEIRO, Renato Janine (org.). Recordar Foucault - os textos do Colóquio Foucault. São Paulo: Brasiliense, 1985.

ROCHA, Heloisa. Recordação para professoras: a história da educação brasileira narrada por Afrânio Peixoto. In GONDRA, José (org.) Dos arquivos à escrita da história. Bragança Paulista: EDUSF, 2002. 
ROUANET, Sergio et al.. O homem e o discurso (A arqueologia de Michel Foucault). $2^{\mathrm{a}}$ edição. Rio de Janeiro: Tempo Brasileiro, 1996.

TABORDA OLIVEIRA, Marcus Aurélio. Educação fisica escolar e ditadura militar no Brasil (1968-1984). Bragança Paulista: EDUSF, 2003.

VAGO, Tarcísio. Cultura escolar, cultivo de corpos. Bragança Paulista: EDUSF, 2002.

Data de Registro 16/01/08

Data de Aceite 18/03/08 
